\title{
Pairwise Trade and Coexistence of Money and Higher-Return Assets*
}

\author{
Tao Zhu ${ }^{\dagger}$ and Neil Wallace ${ }^{\ddagger}$ \\ June 20, 2005
}

*Earlier versions of this paper were circulated under the title, "Cash-in-advance with a Twist."

${ }^{\dagger}$ Department of Economics, Cornell University

${ }^{\ddagger}$ Department of Economics, The Pennsylvania State University 


\begin{abstract}
A new theory of coexistence of money and higher-return assets is set out. It applies to any setting in which some trade involves an exchange of goods for assets and occurs between two people - a buyer and a seller. We show that there exists a function mapping the portfolios of the buyer and the seller to the trade that occurs such that (i) the trade is in the buyer-seller core and (ii) some people are induced to enter the buyer-seller meeting with money.
\end{abstract}

JEL Classification: E40

Keywords: Money; higher-return assets; coexistence.

Running title: Money and higher-return assets 


\section{Introduction}

Almost every applied model designed to study monetary policy contains noninterest-bearing money and higher-return assets. The higher-return assets may be capital, titles to capital, or government bonds. Therefore, in some way or other, such models confront the challenge that Hicks [7] said was the main one facing monetary theory: why is money held when higher-return assets exist? In this paper, we provide a new theory of such coexistence. Our theory assumes that some trade involves an exchange of a good (or goods) for assets and occurs in pairs, between a buyer of a good and a seller. We show that there exists a function mapping the portfolio (of money and higher return assets) brought into the meeting to the trade that occurs such that (i) the trade is in the pairwise core for the meeting and (ii) the trade gives buyers larger payoffs the more money they have. The second property gives potential buyers an incentive to enter pairwise meetings with some money and, thereby, implies coexistence. The first property implies that there is neither individual nor cooperative defection by the pair from the trade.

Why do we need a new theory? Isn't cash-in-advance, the dominant existing theory, adequate? We think not. When trade occurs in pairs, cashin-advance is not in the pairwise core and, therefore, is a strange restriction to impose: it leaves positive gains from trade for the two people in the meeting. When trade occurs in large markets, the main rationale for cash-in-advance models is a Shapley-Shubik trading-post model and an equilibrium in that model with no activity at the posts at which assets other than money can be traded for goods (see, for example, Howitt [8]). Although such inactivity is consistent with a Nash equilibrium in a Cournot-type game because one person has no incentive to place quantity orders on an inactive post, the same argument implies that no trade at all is an equilibrium - a troublesome feature of the model. Dubey and Shubik [5] introduce a refinement which eliminates no trade: there is a small exogenous offer at each post and an equilibrium satisfies the refinement if it is a limit as that exogenous offer approaches zero. Krishna [9] applies a version of that refinement in a setting with money and higher-return assets and shows that the cash-in-advance equilibrium does not satisfy the refinement. Moreover, we suspect that the cash-in-advance equilibrium does not survive other ways of endogenizing activity at potential trading posts. If so, then, even without imposing the core requirement, the cash-in-advance equilibrium is also questionable for large markets. 
The rest of the paper is organized as follows. In section 2 we formally describe our trading procedure against the background of a setting in which safe one-period discount bonds, made available by the government, dominate money in rate-of-return. There, our discussion is partial equilibrium in that we take as given the way people value post-trade assets. In section 3, we demonstrate that our theory actually accomplishes what we claim - namely, that there exist models which have equilibria with valuations of post-trade wealth of the sort we assume in section 2 and that people actually choose to hold money. In section 4 we discuss the generality of our theory and in section 5 we conclude.

\section{Pairwise trade}

The crucial part of our model describes how trade for goods occurs. We assume that it occurs between a buyer and a seller, that it must be spot quid-pro-quo trade, and that there are three distinct and divisible objects potentially involved in trade: a perishable good, money, and one-period bonds that mature (turn into money) at the end of the period.

This pairwise trade should be thought of as taking place against the following sequence of actions in discrete time. Each person begins a date with some money. Then the person can exchange money for bonds at an exogenous price $p \in(0,1)$ in terms of money - each bond being a title to a unit of money at the end of the period. (Imagine that there are vending machines maintained by the government which offer such bonds in exchange for money.) Then, after portfolios are chosen, there is pairwise trade involving assets and goods. Then the bonds mature - automatically turn into moneyand the implied interest payments are financed by a tax on nominal wealth that mimics financing by money creation (inflation). For this setting, we say there is coexistence of money and higher-return assets if not all the money is used to buy bonds - if some people leave the bond-buying stage with some money.

In pairwise meetings, we assume that there are unambiguous buyers and sellers of the good and that there is no asymmetric information except about trading histories. ${ }^{1}$ In particular, preferences and portfolios of assets are known. We let $\left(y_{1}, y_{2}\right)$ denote the pre-trade portfolio of the buyer and let

\footnotetext{
${ }^{1}$ Trading histories are private in a way that precludes any borrowing and lending between people.
} 
$\left(y_{1}^{\prime}, y_{2}^{\prime}\right)$ denote that of the seller, where the first component is money and the second component is bonds measured at maturity value. It is convenient to let $y_{z}=y_{1}+y_{2}$ and $y_{z}^{\prime}=y_{1}^{\prime}+y_{2}^{\prime}$.

We let $(q, x)$ denote a trade, where the first component is the quantity of the good transferred from the seller to the buyer and the second component refers to the quantity of nominal wealth, money and bonds, transferred from the buyer to the seller. Payoffs depend on trades and initial portfolios as follows. The buyer's payoff is $u_{b}(q)+g_{b}\left(y_{z}-x\right)$, while the seller's is $u_{s}(q)+g_{s}\left(y_{z}^{\prime}+x\right)$. Each of the functions $u_{b}, u_{s}, g_{b}$, and $g_{s}$ maps $\mathbb{R}_{+} \rightarrow \mathbb{R}$ and is concave. Also, $u_{s}$ is strictly decreasing (in the amount of the good surrendered), while the remaining functions are strictly increasing. Finally, at least $u_{b}$ or $u_{s}$ is strictly concave. (The assumptions about $u_{b}$ and $u_{s}$ are primitives, while the assumptions about $g_{b}$ and $g_{s}$ have to be confirmed as part of a general equilibrium.)

The trade that occurs is the outcome of the following two-step maximization problem. The first step contains a cash-in-advance constraint, while the second step does not. In the first step, buyer utility is maximized subject to the cash-in-advance constraint and to no trade as a lower bound on seller utility. In the second step, seller utility is maximized subject to a lower bound on buyer utility given by the first step outcome.

Problem 1 First, choose $\left(q_{1}, x_{1}\right)$ to $\max \left\{u_{b}\left(q_{1}\right)+g_{b}\left(y_{z}-x_{1}\right)\right\}$ subject to $x_{1} \leq y_{1}$ and

$$
u_{s}\left(q_{1}\right)+g_{s}\left(y_{z}^{\prime}+x_{1}\right) \geq u_{s}(0)+g_{s}\left(y_{z}^{\prime}\right) .
$$

Then, choose $(q, x)$, the final trade, to $\max \left\{u_{s}(q)+g_{s}\left(y_{z}^{\prime}+x\right)\right\}$ subject to

$$
u_{b}(q)+g_{b}\left(y_{z}-x\right) \geq u_{b}\left(q_{1}\right)+g_{b}\left(y_{z}-x_{1}\right) .
$$

We summarize properties of the solution to problem 1 in the following proposition.

Proposition 1 The final trade, $(q, x)$, that solves problem 1 is unique and is in the buyer-seller core. Moreover, the solution satisfies $\left(q-q_{1}, x-x_{1}\right)$ $\geq(0,0)$ and strictly if and only if the cash-in-advance constraint, $x_{1} \leq y_{1}$, is binding. 
Proof. Existence and uniqueness of the solution are standard. By the constraint $x_{1} \leq y_{1}$ being binding, we mean that the solution to step 1 would be different if it were removed. Suppose first that it is not binding. Then, by definition, the step- 1 trade is in the buyer-seller core. And because the step1 solution is unique, it follows that $\left(q-q_{1}, x-x_{1}\right)=(0,0)$. Now suppose the constraint $x_{1} \leq y_{1}$ is binding. Then, the step- 1 solution is not in the buyer-seller core. Because the step-2 outcome is by definition in that core, it follows that $\left(q-q_{1}, x-x_{1}\right) \neq(0,0)$. And, obviously, $\left(q-q_{1}\right)\left(x-x_{1}\right)>0$. If $x-x_{1}<0$, then $(q, x)$ is a feasible step- 1 trade which gives at least as high a payoff to the buyer as does $\left(q_{1}, x_{1}\right)$ and gives a higher payoff than $\left(q_{1}, x_{1}\right)$ to the seller. It follows that there exists $\varepsilon>0$ such that $(q+\varepsilon, x)$ is feasible in step 1 and gives a higher step- 1 value of the objective than $\left(q_{1}, x_{1}\right)$, a contradiction.

The solution to problem 1 can be depicted in an Edgeworth Box (see figure 1). The box is drawn for an endowment environment in which the buyer starts with none of the good (point $A$ is the initial endowment). The wealth total depicted is $y_{z}+y_{z}^{\prime}$. Notice that for given $\left(y_{z}, y_{z}^{\prime}\right)$, neither the size of the box, nor the endowment point, nor the indifference curve map depends on the composition of the portfolios. However, our selection of a trade does. If the cash-in-advance constraint is not binding in step 1, then the step- 1 outcome is point $B$ and the step- 2 trade is null. Otherwise, the step-1 outcome is a point like $C$ and the final outcome is point $D$.

Problem 1 would not be of much interest - at least, relative to cash-inadvance models - if the cash-in-advance constraint in step 1 were never binding. As might be suspected, that is not generally the case.

Corollary 1 Assume that $g_{b}$ and $g_{s}$ are differentiable. Consider a person who prior to choosing a portfolio will with positive probability be the buyer in some meetings in which no-trade is not in the pairwise core. This person chooses a portfolio so that the cash-in-advance constraint in step 1 of problem 1 is binding in some of this person's pairwise meetings.

Proof. Suppose, by way of contradiction, that the cash-in-advance constraint in step 1 of problem 1 is never binding for the person - whether the person is a buyer or a seller. It follows that the payoff at the choice-ofportfolio stage is some weighted average of the payoff from being a buyer and the payoff from no-trade. (Because step 2 is null, the payoff from being a seller is the same as that of no-trade.) Because no-trade is not in the 


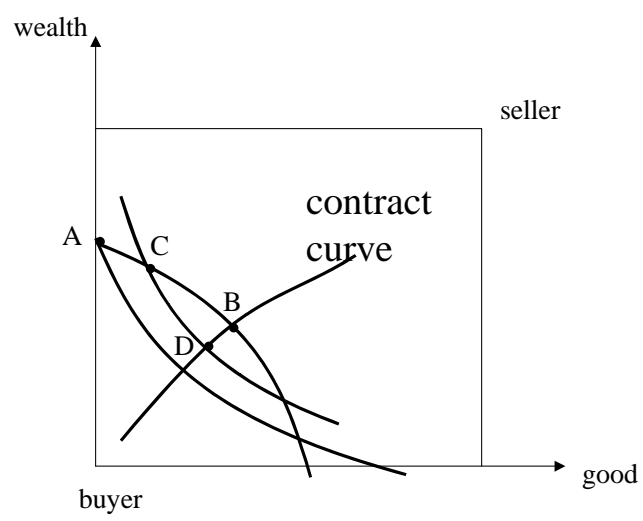

Figure 1: Alternative solutions to problem 1.

pairwise core for some meetings in which the person is a buyer, this person has positive wealth. Now, let $y^{*}=\left(y_{1}^{*}, y_{2}^{*}\right)$ denote the portfolio chosen by the person. Either $y_{1}^{*}=0$ or $y_{1}^{*}>0$. If $y_{1}^{*}=0$, then the cash-in-advance constraint in step 1 of problem 1 is binding when this person is the buyer in a meeting in which no-trade is not in the pairwise core. So suppose $y_{1}^{*}>0$. Then because $p<1, y_{z}=y_{1}+y_{2}$ is strictly decreasing in $y_{1}$ for all $\left(y_{1}, y_{2}\right)$ with $y_{1}+y_{2} / p=y_{1}^{*}+y_{2}^{*} / p$. That implies that the payoff from no-trade is strictly decreasing in money holdings. By the contradicting assumption, it also implies that the payoff from being a buyer is strictly decreasing in money holdings. To see this, first notice that if $\left(q_{1}, x_{1}\right)$ solves step- 1 of problem 1, then (1) is binding in the step-1 problem, which implies that $\left(q_{1}, x_{1}\right)=\left(f\left(x_{1}\right), x_{1}\right)$, where $f\left(x_{1}\right)=u_{s}^{-1}\left[u_{s}(0)+g_{s}\left(y_{z}^{\prime}\right)-g_{s}\left(y_{z}^{\prime}+x_{1}\right)\right]$, a differentiable and concave function. It follows that the step- 1 objective can be written as $F\left(x_{1}, y_{1}, y_{2}\right) \equiv u_{b}\left[f\left(x_{1}\right)\right]+g_{b}\left(y_{1}+y_{2}-x_{1}\right)$. Because $F$ is strictly concave in $x_{1}$, the $x_{1}$ that solves step 1 of problem 1 , denoted $x_{1}^{*}$, is unique and differentiable in $y$. Then, $d F / d y_{1}=F_{1} \cdot d x_{1}^{*} / d y_{1}+g_{b}^{\prime} \cdot(1-1 / p)$. The contradicting assumption implies that $F_{1}\left(x_{1}^{*}, y_{1}^{*}, y_{2}^{*}\right)=0$ and, therefore, that $d F\left(x_{1}^{*}, y_{1}^{*}, y_{2}^{*}\right) / d y_{1}<0$. But that contradicts optimality of $y^{*}$.

Now we turn to some further comments about problem 1. Problem 1 does not describe a two-stage game in which the buyer moves first and the seller, upon acceptance, moves second. For one thing, if it were such a game, then 
the buyer would not have to respect the lower bound on the seller pay-off in (1) because both the buyer and the seller anticipate a second stage that will benefit the seller. Nevertheless, the final trade is weakly implementable. Here is a game, consistent with trade being voluntary, which gives the problem-1 outcome as one equilibrium. The buyer and seller say "cooperate" or "defect" to the problem-1 outcome with "defect" by either person implying no trade in the meeting and "cooperate" by both implying trade according to the problem-1 outcome.

Of course, this game has a very limited strategy space. To implement a core allocation by games with rich strategies, we can follow Perry and Reny [12]. For the alternating-offer game in [12], the observed portfolios of the buyer and the seller can be interpreted as determining the strategies that each person expects the other person to play. In that way, they affect the final outcome. In other words, the portfolios play the role of a coordination device. They can play such a role because the pairwise core is not degenerate.

We do not claim that problem 1 is the only way of selecting a trade consistent with coexistence. ${ }^{2}$ For example, we could assign some small positive gain from trade to the seller in step 1 and some small gain to the buyer in step 2. If those are small enough, then they should be consistent with coexistence. Indeed, because step 2 produces the pairwise-core result, one could conceivably replace our step 1 by something quite a bit different.

Finally, the pairwise and, hence, non-competitive aspect of trade is crucial. The simplest way to see that is to let the size of a meeting grow by replicating the buyer-seller pair in a meeting. If that is done and if we continue to require that the outcome be in the meeting-specific core, then coexistence necessarily disappears as the meeting size grows because the core converges to a competitive equilibrium. In our setting, the way that bonds and money appear in payoffs implies that any competitive equilibrium has money and bonds at maturity value trading one for one. And that, of course, is not consistent with coexistence.

Under some additional assumptions - about the functions $g_{b}$ and $g_{s}$, the distribution of wealth at the start of the period, and the kinds of meetings

\footnotetext{
${ }^{2}$ And, we are obviously not claiming that problem 1 is the only way to achieve an outcome in the pairwise core. Another way to achieve a pairwise core outcome is for people to ignore the difference between money and bonds at maturity (drop the cash-inadvance constraint in step 1 of problem 1) and another is to replace the cash-in-advance constraint with a bonds-in-advance constraint. Of course, neither of these will produce coexistence.
} 
that occur - we could show coexistence by showing that some people leave the bond-buying stage with some money. However, because any such proposition requires more assumptions than those so far made, we prefer to demonstrate coexistence as part of a general equilibrium.

\section{Coexistence in general equilibrium}

We describe coexistence for two examples, both of which use the familiar matching environment originally set out by Shi [14] and Trejos and Wright [16]. Time is discrete. There is a non-atomic, unit measure set of each of $N \geq 3$ types of people and there are $N$ distinct produced and perishable types of divisible goods at each date. A type $n$ person, $n \in\{1,2, \ldots, N\}$, produces type $n$ good and consumes only type $n+1$ goods (modulo $N$ ) and has period utility $u\left(q_{n+1}\right)-q_{n}$, where $q_{n+1} \in \mathbb{R}_{+}$is consumption of good $n+1$ and $q_{n} \in \mathbb{R}_{+}$is production of good $n$. The function $u: \mathbb{R}_{+} \rightarrow \mathbb{R}_{+}$is strictly concave, strictly increasing, continuously differentiable and satisfies $u(0)=0$ and $u^{\prime}(\infty)=0$. In addition, $u^{\prime}(0)$ is sufficiently large.

The first example is the standard version of the above model in which people are infinitely lived and in which the state of the economy is a nondegenerate distribution of wealth. The second example is a 2-date lived, overlapping-generations (OLG) version of the matching model in which there is no such state variable.

We start with the first example. As is standard, people maximize the expected value of discounted period utility and there is one random pairwise meeting per date. In this version, aside from the price of bonds, there are three exogenous nominal quantities: an upper bound on individual wealth, the size of the smallest unit of an asset, and average wealth. We normalize by letting the smallest unit of an asset be unity so that the set of possible individual wealth holdings is $\mathbf{Z}=\{0,1,2, \ldots, Z\}$. We denote average wealth per type by $\bar{z}>0$ and assume only that $\bar{z}$ and $Z / \bar{z}$ are sufficiently large. (The first insures that the indivisibility is not too severe and the second that the bound is not too severe). And because assets are indivisible, we permit lotteries at the portfolio choice stage when people buy one-period discount bonds at the price $p$, in pairwise trade when trade occurs according to problem 1, and for the proportional tax on wealth that is used to finance interest payments. ${ }^{3}$

\footnotetext{
${ }^{3}$ There should be no concern about the disparity between these assumptions about
} 
We define a steady state to be a fixed point of the relevant version of the usual mapping studied in heterogeneous agent models, a mapping from "endof-period" value functions and "beginning-of-period" distributions to sets of "end-of-period" distributions and "beginning-of-period" value functions. (For the detailed definition, see [18], an unpublished appendix to this paper.) There are four steady-state objects. Two pertain to the start of a date, just prior to the choice of a portfolio: $w: \mathbf{Z} \rightarrow \mathbb{R}$, where $w(z)$ is the expected discounted value of having wealth $z$; and $\pi: \mathbf{Z} \rightarrow[0,1]$, where $\pi(z)$ is the fraction of each specialization type with wealth $z$. The other two pertain to the situation after the choice of portfolios. Let $\mathbf{Y}=\left\{y=\left(y_{1}, y_{2}\right) \in \mathbf{Z} \times \mathbf{Z}\right.$ : $\left.y_{1}+y_{2} \leq Z\right\}$, the set of possible portfolios after bond purchases that satisfies the restriction that total nominal wealth does not exceed $Z$. The other two objects are $h: \mathbf{Y} \rightarrow \mathbb{R}$, where $h(y)$ is the expected discounted value of having the portfolio $y$, and $\theta: \mathbf{Y} \rightarrow[0,1]$, where $\theta(y)$ is the fraction of each specialization type with portfolio $y$. In [18], we prove

Proposition 2 If $u^{\prime}(0), \bar{z}$, and $Z / \bar{z}$ are large enough and if $p$ is sufficiently close to 1 , then there exists a steady state $(w, h, \theta, \pi)$ with $w$ bounded (independently of $Z, \bar{z}$, and $p$ ), strictly increasing, and strictly concave and with $\pi$ having full support.

The logic of the proof is as follows. If $p=1$, then the model is a moneyonly model with take-it-or-leave-it offers by buyers, the model for which Zhu [17] shows that the conclusions of proposition 2 hold. Using the same kind of argument, we show that if $p=1$, then the above mapping has index 1 for some appropriately defined fixed-point index. ${ }^{4}$ That and upper-hemicontinuity of the mapping in $p$ imply existence for $p$ near 1 via an argument that is analogous to the implicit function theorem. ${ }^{5}$ We also show in [18] that a proposition-2 steady state implies coexistence.

assets and those used in section 2. A bound on wealth is consistent with section 2 provided the pairwise core is defined taking the bound as a given. As regards the indivisibility of assets, with lotteries and with a concave value function defined on $\mathbf{Z}$, the functions $g_{s}$ and $g_{b}$ in section 2 can be taken to be the extension of that function to $[0, Z]$ via linear interpolation. With that interpretation, proposition 1 , which did not require strict concavity of $g_{s}$ or $g_{b}$, is unchanged. However, corollary 1 may not hold, because $g_{s}$ and $g_{b}$ are not differentiable. (They are differentiable in the second example.)

${ }^{4}$ Here, we make essential use of the form of step 1 of problem 1.

${ }^{5}$ The main barrier to producing an existence proof for arbitrary $p$ is that the mapping used does not preserve concavity of value functions for an arbitrary $p$. (The problem is that sellers with different quantities of assets who face a given buyer end up with different 
Corollary 2 If $u^{\prime}(0), \bar{z}$, and $Z / \bar{z}$ are large enough, then in a proposition2 steady state a positive measure of people leave the bond-buying stage with some money.

This proof does not rely on $p$ being near 1 . It shows that sufficiently rich people leave the bond-buying stage with some money. The full-suppport property of $\pi$ in proposition 2 assures that there are such people.

Now we turn to the second example. Here, we embed the kind of centralized and decentralized trade in Lagos and Wright [11] in an OLG model. We normalize by assuming that the initial old of each specialization type in the aggregate hold a unit amount of divisible money. Each two-period lived member of generation $t$ of type $n$, young at $t$ and old at $t+1$, maximizes the expected value of $U\left(c_{t}\right)+u\left(q_{n+1, t}\right)-q_{n, t}+V\left(c_{t+1}\right)$, where $c_{t}$ is consumption of the single perishable, "centralized-trade" date- $t$ good and where the $q$ 's are the date- $t$ specialized goods of the matching model. Each such person is endowed with $\omega$ units of the single "centralized-trade" date- $t$ good and none of the single "centralized-trade" date- $t+1$ good. The function $u$ is that described above. We assume that $U$ and $V$ are increasing, concave, and continuously differentiable. In addition, $V$ is strictly increasing.

Events at date $t$ occur as follows. First, there is centralized competitive trade among everyone - the old and the young. In addition to choosing $c_{t}$, each young person chooses a portfolio of money and bonds exactly as in section 2. Then, there are pairwise meetings at random only among the young (the old have died). This trade is conducted as described in problem 1 and the payoffs are determined by the realization of $u\left(q_{n+1, t}\right)-q_{n, t}$ for each person. Finally, a proportional tax is imposed on nominal wealth to finance interest on bonds.

This model has three steady-state objects. There is a price of money, $v$, in terms of the centralized market good. (This scalar replaces $(w, \pi)$ in the model above.) And there are analogues of $h$ and $\theta$ in the above model, where $h(y)$ is the discounted value of the portfolio $y=\left(y_{1}, y_{2}\right)$ and $\theta$ is the distribution of such portfolios. Because our goal is simply to produce another example of coexistence, nothing is lost by specializing the model by assuming that the young do not consume in the centralized market $(U(\cdot) \equiv 0)$. This immediately implies that any steady state with valued money has $v=\omega$. For such a version, all that is left is the determination of $h$ and $\theta$.

step-1 trades.) And, without concavity, we do not know how to show that there is a steady state with trade. 
The conditions for equilibrium under $U(\cdot) \equiv 0$ are simple. Let $w(z) \equiv$ $V((1-\tau) z \omega)$, where $z$ is nominal wealth after pairwise trade but before the $\operatorname{tax}, \tau$, is levied. Consider a person with portfolio $y$ who meets someone with $y^{\prime}$. If a buyer, then the person's payoff (the buyer's payoff in step 1 of problem 1) is

$$
f\left(y, y^{\prime}\right)=\max _{(q, m)} u(q)+w\left(y_{z}-m\right)
$$

subject to $-q+w\left(y_{z}^{\prime}+m\right) \geq w\left(y_{z}^{\prime}\right)$ and $m \leq y_{1}$; if a seller, then the payoff (the seller's final payoff in problem 1 ) is

$$
g\left(y, y^{\prime}\right)=\max _{(q, m)}-q+w\left(y_{z}+m\right)
$$

subject to $u(q)+w\left(y_{z}^{\prime}-m\right) \geq f\left(y^{\prime}, y\right)$ and $m \leq y_{z}^{\prime}$. Hence, if the distribution of portfolios is $\theta$, the value of holding $y$ just before pairwise meetings is

$$
h(y)=\frac{N-2}{N} w\left(y_{z}\right)+\frac{1}{N} \int f\left(y, y^{\prime}\right) \theta\left(d y^{\prime}\right)+\frac{1}{N} \int g\left(y, y^{\prime}\right) \theta\left(d y^{\prime}\right) .
$$

Let

$$
G(h)=\left\{y: y \in \arg \max h(y) \text { subject to }\left(y_{1}+p y_{2}\right) \leq 1\right\} .
$$

Because all the young are identical when they choose a portfolio, one might think that there is a steady state with a degenerate $\theta$. However, that may not be the case. For the same reason as in the model above, $h$ cannot be shown to be concave in the choice of a portfolio. Therefore, $G(h)$ may not be a singleton and randomization over the elements of $G$ may be required for equilibrium. ${ }^{6}$

Definition 1 Assume $U(\cdot) \equiv 0$. An equilibrium is $(\theta, h)$ such that (i) $h$ and $\theta$ satisfy (3) when $\tau=1-\int \frac{1}{1+y_{2}(1-p)} \theta(d y)$; and (ii) the support of $\theta$ is a subset of $G(h)$.

We have the following result regarding existence.

\footnotetext{
${ }^{6}$ Although a non degenerate $\theta$ can be part of an equilibrium in this OLG model, $\theta$ is not, of course, a state variable of the model. The fact that this model has no state variable is a consequence of the assumption that people live for only two dates. That implies that all those who enter the centralized market with wealth are old and, therefore, at a corner; they want to sell all their wealth. That corner is the analogue in this OLG model of the quasi-linear preferences in Lagos and Wright [11].
} 
Proposition 3 There exists $(\theta, h)$ that satisfies definition 1.

Proof. Let $\Theta$ be the set of probability measures on $[0,1] \times[0,1 / p]$ and let $\digamma$ be the set of real continuous functions on $[0,1] \times[0,1 / p]$. Definition 1 induces a mapping $T$ from $\Theta$ to $\Theta$ as follows. First, (3) defines a mapping $\theta \mapsto T_{1}(\theta)$ from $\Theta$ to $\digamma$. (This mapping subsumes the dependence of $h$ on $\tau$ via the expression for $\tau$ in definition 1.) Second, the set of all randomizations over $G(h)$ (see (4)) defines a mapping $h \mapsto T_{2}(h)$ from $\digamma$ to $\Theta$. It turns out that $T_{2}(h)=\arg \max _{\theta^{\prime}} \int h(y) \theta^{\prime}(d y)$, where $\theta^{\prime} \in \Theta$ and satisfies $\theta^{\prime}\{y$ : $\left.y_{1}+p y_{2}>1\right\}=0$. Let $T(\theta)=T_{2}\left(T_{1}(\theta)\right)$. Let $\Theta$ be equipped with the weak* topology and let $\digamma$ be equipped with the sup-norm topology. By standard arguments, $T_{1}$ is continuous and $T_{2}$ is upper hemicontinuous, compact-valued, and convex-valued. Therefore, $T$ is upper hemicontinuous, compact-valued, and convex-valued. Then by Fan's fixed point theorem, there exists a fixed point of $T$. If $\theta$ is such a fixed point, then, $\left(\theta, T_{1}(\theta)\right)$ is an equilibrium.

The following corollary implies coexistence.

Corollary 3 If $u^{\prime}(0)>2 N / p$ and $(\theta, h)$ satisfies definition 1 , then $\int_{y_{1}=0} \theta(d y)<$ 1.

Proof. By way of contradiction, suppose that every person who is met with positive probability has the portfolio $\left(0, \frac{1}{p}\right)$. We show that this implies that $\left(0, \frac{1}{p}\right) \notin G(h)$. In particular, we show that this implies $\delta(\varepsilon) \equiv h\left(\varepsilon, \frac{1-\varepsilon}{p}\right)-$ $h\left(0, \frac{1}{p}\right)>0$ for sufficiently small $\varepsilon$. There are three kinds of meetings to consider.

(i) The person is neither a buyer nor a seller. Then the payoff difference between having the portfolio $\left(\varepsilon, \frac{1-\varepsilon}{p}\right)$ and having $\left(0, \frac{1}{p}\right)$ is $w\left(\frac{1}{p}+\varepsilon-\frac{\varepsilon}{p}\right)-w\left(\frac{1}{p}\right)$ $>w\left(\frac{1-\varepsilon}{p}\right)-w\left(\frac{1}{p}\right) \equiv-A_{1}(\varepsilon)$.

(ii) The person is a seller. Because the buyer holds $\left(0, \frac{1}{p}\right)$, step- 1 of problem 1 is null. This implies that a final trade that is feasible for the seller with portfolio $\left(0, \frac{1}{p}\right)$ is also feasible if the seller has $\left(\varepsilon, \frac{1-\varepsilon}{p}\right)$. It follows that the payoff difference is bounded below by $-A_{1}(\varepsilon)$ because $\frac{1}{p}$ is a lower bound on the wealth of the seller with $\left(0, \frac{1}{p}\right)$ and because $w$ is concave.

(iii) The person is a buyer. Because the seller holds $\left(0, \frac{1}{p}\right)$, a feasible step1 trade for a buyer with $\left(\varepsilon, \frac{1-\varepsilon}{p}\right)$ is $\varepsilon$ in exchange for $w\left(\frac{1}{p}+\varepsilon\right)-w\left(\frac{1}{p}\right) \equiv A_{2}(\varepsilon)$ amount of the good. Hence, the step-1 payoff to the buyer with $\left(\varepsilon, \frac{1-\varepsilon}{p}\right)$ is 
bounded below by $u\left(A_{2}\right)+w\left(\frac{1-\varepsilon}{p}\right)$, while the buyer with $\left(0, \frac{1}{p}\right)$ gets the payoff $w\left(\frac{1}{p}\right)$. Hence, the payoff difference is bounded below by $u\left(A_{2}\right)-A_{1}(\varepsilon)$.

Now, assembling these results, we have

$$
\delta(\varepsilon)>\frac{1}{N} u\left(A_{2}(\varepsilon)\right)-A_{1}(\varepsilon)>\frac{A_{2}(\varepsilon)}{N} u^{\prime}\left(A_{2}(\varepsilon)\right)-A_{1}(\varepsilon),
$$

where the second inequality follows from $u(0)=0$ and the mean value theorem applied to $u$. Now, again by the mean value theorem, $A_{1}(\varepsilon)=\frac{\varepsilon}{p} f_{1}(\varepsilon)$, where $f_{1}(\varepsilon)$ is the derivative of $w$ evaluated at some point in the interval $\left[\frac{1}{p}-\frac{\varepsilon}{p}, \frac{1}{p}\right]$; and $A_{2}(\varepsilon)=\varepsilon f_{2}(\varepsilon)$, where $f_{2}(\varepsilon)$ is the derivative of $w$ evaluated at some point in the interval $\left[\frac{1}{p}, \frac{1}{p}+\varepsilon\right]$. Therefore,

$$
\delta(\varepsilon)>\frac{\varepsilon}{p} f_{1}(\varepsilon)\left[\frac{f_{2}(\varepsilon)}{(N / p) f_{1}(\varepsilon)} u^{\prime}\left(A_{2}(\varepsilon)\right)-1\right] .
$$

Because $V$, and, hence, $w$, is continuously differentiable, $\lim _{\varepsilon \rightarrow 0} f_{2}(\varepsilon)=$ $\lim _{\varepsilon \rightarrow 0} f_{1}(\varepsilon)=w^{\prime}\left(\frac{1}{p}\right)=V^{\prime}(\omega)>0$. Therefore, for all sufficiently small $\varepsilon$, $f_{2}(\varepsilon)>f_{1}(\varepsilon) / 2$. Hence, for all $\operatorname{such} \varepsilon$,

$$
\delta(\varepsilon)>\frac{\varepsilon}{p} f_{1}(\varepsilon)\left[\frac{1}{2(N / p)} u^{\prime}\left(A_{2}(\varepsilon)\right)-1\right] .
$$

But, then, because $A_{2}(\varepsilon)>0$ and $\lim _{\varepsilon \rightarrow 0} A_{2}(\varepsilon)=0, u^{\prime}(0)>2 N / p$ implies $\delta(\varepsilon)>0$ for all sufficiently small $\varepsilon$.

A few comments are in order about this proof. If the setting were such that a person at the portfolio stage was a buyer for sure, then only the third step of the proof would be needed and the proof would show that a prospective buyer has a dominant strategy to enter pairwise trade with some money. If not, then the buyer's payoff would be $u(0)+w(1 / p)$ even though, in terms of figure 1, the final trade would give the point on the contract curve on the buyer's indifference curve through the endowment point $A$. If the buyer instead enters trade with a small amount of money, then the buyer receives a problem-1, step-1 payoff that has a small amount of consumption and almost as much wealth. That makes $u^{\prime}(0)$ relevant for the comparison between the two payoffs. In the setting of the above matching model in which a person at the portfolio-choice stage does not know whether he will be a buyer or a seller, we use the assumption that no other buyer has money to help us bound the loss to a seller from having entered pairwise trade with some money. 


\section{Generality of the theory}

As should be evident, problem 1 is general in the sense that it can be applied against the background of almost any model with pairwise trade that takes place after portfolios are chosen. Moreover, it can be applied to different assets and can be combined with markets in assets. The simplest way to introduce a market in assets is to interpret an equilibrium as one in which the equilibrium quantity of bonds is treated as exogenously supplied by the government to a competitive market in money and bonds, a market which replaces the vending machines mentioned above. Clearly, $p$ is then an equilibrium price of bonds.

Using such a market formulation, the exogenous stock of higher-return assets need not be government bonds. For example, there could be a stock of real assets - assets with real dividends. Of course, for such a model, the nature of the dividends, including when they are realized, has to be described. In the setting with some goods trade in the centralized market, it is simple to assume that the dividends are in the form of the centralized market good. Notice, by the way, that in such a model, achieving coexistence is the same as achieving existence of an equilibrium in which money is valued.

The model can also be used to get imperfect substitutability between the monies of different countries - even under fixed exchange rates. ${ }^{7}$ To adapt it to that purpose, let $p=1$ and assume that the "bonds" do not automatically turn into money. Instead, let them have a distinct and permanent color so that they are a distinct money. Also, let the vending machines maintain a fixed exchange rate between the two monies by allowing people to buy or sell one money for the other. If in problem 1 we assume that the favored money is the seller's "home" money, then buyers who anticipate meeting a seller from a particular country will want to acquire the seller's home money.

\section{Concluding remarks}

We have posed the coexistence challenge in as stark a form as is imaginable. There are two reasons for doing that. First, and most important, almost every model used to study monetary policy has such coexistence even if the higher-return assets are not titles to money. Second, assets that resemble

\footnotetext{
${ }^{7} \mathrm{~A}$ two-money precurser of the theory appears in [13]. There, however, portfolios are so special that either step 1 or step 2 of problem 1 is necessarily null.
} 
the bonds in the above setting have at times appeared in actual economies. During the First World War, both the U.S. and France issued small denomination, payable-to-the-bearer bonds and in neither instance did the bonds drive out money (for the French experience, see Makinen and Woodward [10]). ${ }^{8}$ The standard applied model, a cash-in-advance model, can meet the coexistence challenge in that stark form. However, as we have suggested, it shuts down markets in a way that is not robust to some ways of modeling whether markets are active and is not consistent with trades being in meeting-specific cores.

We provide an alternative way to achieve coexistence. The alternative depends on some trade occurring in two-person meetings. For such trade, we show how to make a selection from the implied pairwise core so that what happens in a meeting depends on the compositions of the portfolios brought into the meeting in such a way as to give potential buyers an incentive to enter the meeting with some money.

If we agree that trade should be modeled so that gains from trade are not left on the table in meetings, then we have a limited set of options available to explain coexistence. Those who insist on large meetings (competitive trade) must depart from the stark way we have posed the coexistence challenge. Departures would somehow have to reinterpret the coexistence challenge so that the payoffs on other assets do not dominate money in so obvious a way.

One approach appeals to legal restrictions. It assumes that government bonds are not marketable - perhaps, because they are large-denomination or are book-entry bonds - and that legal restrictions preclude intermediation that converts such bonds into small denomination, payable-to-the-bearer instruments. However, that approach does not account for episodes like the one that Makinen and Woodward describe. Moreover, such legal restrictions vanished in the U.S. in the early 1970's. A variant is to assume that the government requires payment in money (see Aiyagari et. al. [1] for a version in which people meet in pairs and in which some meeting partners turn out to be the government.) Another approach is to adapt Freeman's counterfeiting idea which he applied to titles to capital (see [6]): assume that bonds are easier to counterfeit than money. Still another is to impose some transaction costs at the bond-buying stage. All of these are very different from what we currently see in applied models. Even the transaction-cost option

\footnotetext{
${ }^{8}$ Anecdotes suggest that bonds sometimes, but rarely, traded for goods in those episodes.
} 
is very different from assuming that some trades require money as in the Baumol [4] and Tobin [15] inventory models and in their general equilibrium descendents - for example, Alvarez, Atkeson, and Kehoe [2] and Alvarez, Lucas, and Weber [3].

Readers who are willing to have some trade be in pairs now have another option. They can adopt problem 1 or some variant of it and use it as their model of coexistence. However, in using any such model to study the welfare consequences of different policies, a question arises: Should the trading procedure in pairwise meetings be regarded as a policy? We have no firm view on that question.

\section{References}

[1] S. R. Aiyagari, N. Wallace, and R. Wright, Coexistence of money and interest-bearing securities, J. of Monetary Economics 37 (1996), 397419 .

[2] F. Alvarez, A. Atkeson, and P. Kehoe, Money, interest rates, and exchange rates in endogenously segmented markets, J. of Political Economy 110 (2002), 73-112.

[3] F. Alvarez, R. Lucas, and W. Weber, Interest rates and inflation, American Economic Review 91-2 (2001), 219-225.

[4] W. Baumol, The transactions demand for cash: an inventory theoretic approach. Quarterly J. of Economics 66 (1952), 545-556.

[5] P. Dubey and M. Shubik, The non-cooperative equilibria of a closed trading economy with market supply and bidding strategies. J. of Econ. Theory 17 (1978), 1-20.

[6] S. Freeman, Transaction costs and the optimal quantity of money, J. of Political Economy 93 (1985), 146-157.

[7] J. Hicks, A suggestion for simplifying the theory of money, Economica N.S. 2 (February, 1935), 1-19.

[8] P. Howitt, Stability and the quantity theory, J. of Political Economy 82 (1974), 133-151. 
[9] R. V. Krishna, Non-robustness of the cash-in-advance equilibrium in the trading-post model, Economics Bulletin, 5 (2005), 1-5.

[10] G. Makinen and T. Woodward, Some anecdotal evidence relating to the legal restrictions theory of the demand for money, J. of Political Economy 94 (1986), 260-265.

[11] R. Lagos and R. Wright, A unified framework for monetary theory and policy analysis, J. of Political Economy 113 (2005), 463-484.

[12] M. Perry and P. Reny: A noncooperative view of coalition formation and the core, Econometrica 62 (1994), 795-817.

[13] B. Ravikumar and N. Wallace, A benefit of uniform currency, manuscript, The Pennsylvania State University, 2001.

[14] S. Shi, Money and prices: a model of search and bargaining, J. of Econ. Theory 67 (1995), 467-498.

[15] J. Tobin, The interest-elasticity of transactions demand for cash, Review of Economics and Statistics 38 (1956), 241-247.

[16] A. Trejos and R. Wright, Search, bargaining, money and prices, J. of Political Economy 103 (1995) 118-141.

[17] T. Zhu, Existence of a monetary steady state in a matching model: indivisible money, J. of Econ. Theory 112 (2003), 307-324.

[18] T. Zhu and N. Wallace, Appendix to "Pairwise Trade and Coexistence of Money and Higher-Return Assets," manscript, The Pennsylvania State University, 2005. 